\title{
Application of Reverse Micelles of Alkyl Glucosides to Synthesis of Silver Nanoparticles
}

\author{
Hidetaka Noritomi $^{1 *}$, Saori Miyagawa ${ }^{1}$, Naohiro Igari ${ }^{1}$, \\ Hiroaki Saito $^{2}$, Satoru Kato ${ }^{1}$ \\ ${ }^{1}$ Department of Applied Chemistry, Tokyo Metropolitan University, Hachioji, Japan \\ ${ }^{2}$ GUN EI Chemical Industry CO., LTD., Takasaki-shi, Japan \\ Email: "noritomi@tmu.ac.jp
}

Received August 3, 2013; revised September 22, 2013; accepted October 12, 2013

Copyright (C) 2013 Hidetaka Noritomi et al. This is an open access article distributed under the Creative Commons Attribution License, which permits unrestricted use, distribution, and reproduction in any medium, provided the original work is properly cited.

\begin{abstract}
Silver nanoparticles were prepared in reverse micelles of alkyl glucosides by the injection method. The TEM image showed that the obtained silver nanoparticles displayed a wide variety of shapes. The size of silver nanoparticles was strongly dependent upon the kind of reducing agents, and tended to slightly increase with an increase in reaction temperature. The size of silver nanoparticles was hardly dependent upon the molar ratio of water to surfactant and the alkyl chain length of surfactants. Silver nanoparticles having various shapes were obtained at high concentration by the solid-liquid extraction method. The resultant silver colloid could be preserved for at least one month without precipitation.
\end{abstract}

Keywords: Silver Nanoparticle; Reverse Micelle; Alkyl Glucoside; Injection Method; Solid-Liquid Extraction Method

\section{Introduction}

The applications of silver nanoparticles have widely been investigated, since they exhibit some profitable properties such as catalysis [1], antibacterial agent [2], nanoparticle colorant [3], nanopaste for printed electronics [4], and substrates for surface-enhanced Raman scattering [5]. The colors of silver nanoparticles result from changes of LSPR induced by their size and shape.

In order to produce metal nanoparticles, many physical or chemical techniques such as coprecipitation, gasevaporation, sol-gel method, and sputtering have been developed so far [6]. Additionally, more attention has been paid on the preparation of metal nanoparticles in reverse micelles [7]. Reverse micelles are thermodynamically stable nanometer-sized aggregates of surfactant molecules dispersed in a hydrophobic organic phase like octane, and can form w/o type microemulsions containing a small amount of water in their centers. The preparation of nanoparticles using reverse micelles is a kind of build-up method, and does not require a special apparatus and extreme conditions of temperature and pressure. In order to synthesize silver nanoparticles in

\footnotetext{
${ }^{*}$ Corresponding author.
}

reverse micelles, ionic surfactants such as cetyltrimethylammonium bromide (CTAB) and sodium bis(2-ethylhexyl) sulfosuccinate (AOT) have mainly been used [811]. However, those surfactants have several types of toxicity to aquatic organisms and pollute the environment $[12,13]$.

In our previous work, we have reported that silver nanoparticles are prepared in reverse micelles of sucrose fatty acid esters by using the conventional injection method, and the production amount of silver nanoparticles per the reaction volume is drastically enhanced by the novel solid-liquid extraction method [14,15]. Sucrose fatty acid esters are commercial food grade nonionic surfactants, and are biodegradable and nonhazardous to the environment [16]. In the present work, we examined the preparation of silver nanoparticles in reverse micelles of alkyl glucosides to address how the preparation conditions such as the molar ratio of water to surfactant, the kind of reducing agents, the reaction temperature, and the alkyl chain length of surfactants affect the size and shape of silver nanoparticles, since alkyl glucosides have biodegradability and biocompatibility and are widely used as a detergent for dishes and a shampoo. 


\section{Experimental}

\subsection{Materials}

Silver nitrate, hydrazinium hydroxide, and sodium borohydride were the guaranteed reagents of Kanto Chemicals (Tokyo, Japan). As alkyl glucoside (AG), n-heptyl glucoside (AG7), n-octyl glucoside (AG8L), 2-ethylhexyl glucoside (AG8B), n-nonyl glucoside (AG9), ndecyl glucoside (AG10), n-undecyl glucoside (AG11), and $n$-dodecyl glucoside (AG12) were supplied from GUN EI Chemical Industry (Gunma, Japan). The hydrophilic group of AG consisted of monoglucoside (75\%), diglucoside (20\%), and triglucoside (5\%). Figure 1 shows the structure of AG. The surfactant was used without further purification. Isooctane and n-butanol were from Kanto Chemicals (Tokyo, Japan), and were of analytical grade.

\subsection{Synthesis of Silver Nanoparticles by Injection Method}

The reverse micellar solutions containing reducing agent and $\mathrm{AgNO}_{3}$ were prepared by injecting the required amounts of the corresponding aqueous solution into the solution of n-butanol/isooctane $(3: 7(v / v))$ containing AG, and then were used for the preparation of nanoparticles within a few minutes.

The preparation of nanoparticles was achieved by mixing equal volumes of two reverse micellar solutions at the same water concentration, one containing an aqueous solution of $\mathrm{AgNO}_{3}$ and the other containing an aqueous solution of hydrazine or sodium borohydride as a reducing agent.

The preliminary study indicated that the synthesis of particles finished within $1 \mathrm{~h}$. In order to evaluate the dispersion of resultant particles, the samples for various analyses were taken after $3 \mathrm{~h}$. In the present work, the concentration of AG based on the overall volume of reverse micellar solution was fixed at $50 \mathrm{mM}$. As a typical condition, the concentrations of $\mathrm{AgNO}_{3}$ and hydrazine or sodium borohydride in the water pool of reverse micelles were 0.1 and $1.0 \mathrm{M}$, respectively, and the temperature was fixed at $25^{\circ} \mathrm{C}$.

\subsection{Synthesis of Silver Nanoparticles by Solid-Liquid Extraction Method}

The preparation of nanoparticles was carried out by

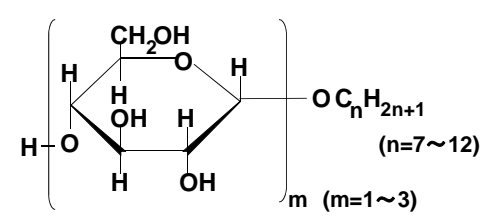

Figure 1. Structure of alkyl glucoside. adding a certain amounts of $\mathrm{AgNO}_{3}$ powder and sodium borohydride powder into the reverse micellar solution.

Since the preliminary study indicated that the synthesis of particles finished at $25^{\circ} \mathrm{C}$ after $3 \mathrm{~h}$, and no residual solid reactants existed in the reaction medium, the samples for various analyses were taken after $3 \mathrm{~h}$. In the present work, the concentrations of AG12 and water based on the overall volume of reverse micellar solution were fixed at 50 and $40 \mathrm{mM}$, respectively. As a typical condition, the overall concentrations of $\mathrm{AgNO}_{3}$ and sodium borohydride were 0.1 and $1.0 \mathrm{M}$, respectively, and the temperature was fixed at $25^{\circ} \mathrm{C}$.

\subsection{Observation of Silver Nanoparticles}

The TEM micrograph was obtained using a JEOL JEM-2000FX electron microscope operating at $200 \mathrm{kV}$. The sample for TEM was prepared by placing a drop of colloidal solution onto the standard carbon-coated copper grids and drying it under vacuum. The UV-vis spectra of the reverse micellar solutions containing nanoparticles were measured by UV/vis spectrophotometer (Ubest-55, Japan Spectroscopic Co. Ltd.) with a $10 \mathrm{~mm}$ quartz cell.

\section{Results and Discussion}

\subsection{Preparation of Silvar Nanoparticles through Injection Method}

We have previously reported that AG12 can form stable reverse micelles in AG12/n-butanol/isooctane system at $3.3 \mathrm{mM}$ AG12 or more, and has the significant solubilization ability for water miscible dyes [17]. In the present work, we have first examined the synthesis of silver nanoparticles in AG12 reverse micelles by the injection method. Figure 2 shows UV-visible absorption spectrum of silver nanoparticles after synthesis with hydrazine in AG12 reverse micelles for $3 \mathrm{~h}$ by the injection method.

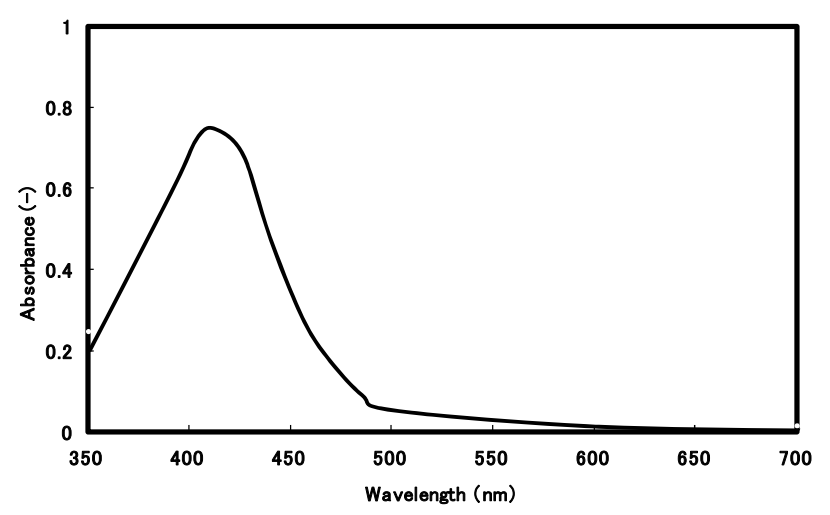

Figure 2. Absorption spectrum of silver nanoparticles prepared in AG12 reverse micelles by the injection method: $\left[\mathrm{AgNO}_{3}\right]_{\mathrm{wp}}=0.1 \mathrm{M} ;\left[\mathrm{N}_{2} \mathrm{H}_{5} \mathrm{OH}\right]_{\mathrm{wp}}=1.0 \mathrm{M}$; n-butanol/isooctane containing $50 \mathrm{mM}$ AG12 and $250 \mathrm{mM} \mathrm{H}_{2} \mathrm{O}$; reaction temperature $=25^{\circ} \mathrm{C}$; reaction time $=3 \mathrm{~h}$. 
The color of the solution after synthesis was yellow, and its UV-visible absorption spectrum exhibited the peak around $410 \mathrm{~nm}$, which corresponds upon the LSPR of silver nanoparticles [18]. The peak steeply increased with an increase in reaction time, and reached a plateau around $1 \mathrm{~h}$. Furthermore, in order to assess the stability in the dispersion of resultant particles after their formation, the preparation of silver nanoparticles was carried out for $3 \mathrm{~h}$ in the present work.

Figure 3 shows the typical transmission electron micrograph and size distribution of silver nanoparticles when silver nanoparticles were prepared with hydrazine in AG12 reverse micelles at $25^{\circ} \mathrm{C}$ for $3 \mathrm{~h}$ by the injection method. The TEM image shows that the obtained silver nanoparticles display a wide variety of shapes with a mean diameter of $14 \pm 3.7 \mathrm{~nm}$. AG12 exhibited the sufficient solubilization and dispersion capabilities in the present system, since reactant solutions could spontaneously be solubilized into the organic solution containing AG12 and the generated silver nanoparticles were relatively stabilized at room temperature for at least one month, similar to the case of silver nanoparticles in reverse micelles of sucrose fatty acid esters [14].

\subsection{Dependence of Water Content upon Size of Silver Nanoparticles}

It has been well known that the molar ratio of water to surfactant (Wo value) in the reverse micellar system affects the size of reverse micelles and the properties of water pools such as polarity, viscosity, and so on [19]. Consequently, the studies regarding the relationship between the size of nanoparticles prepared by the reverse micellar system and the Wo value have been reported [20,21]. According to the composition of reverse micellar system and the kind of nanoparticles, the size of nanoparticles increases, decreases, or does not change with
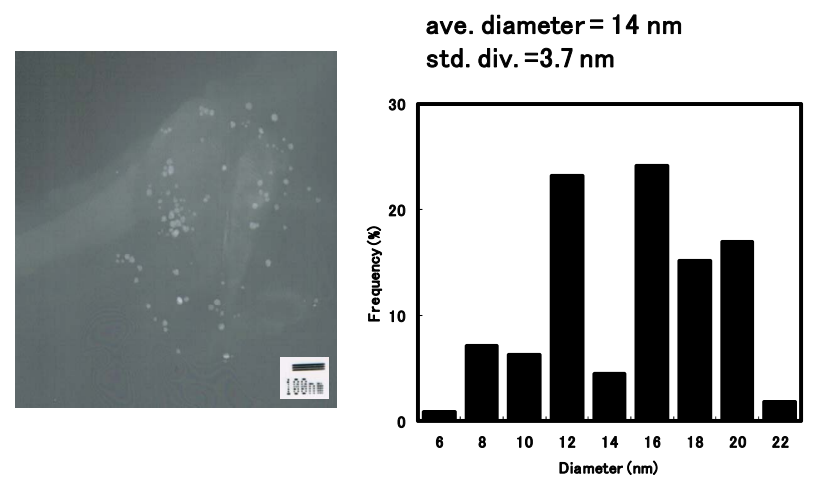

Figure 3. Transmission electron micrograph and particle size distribution of silver nanoparticles synthesized in AG12 reverse micelles by the injection method: $\left[\mathrm{AgNO}_{3}\right]_{\mathrm{wp}}=\mathbf{0 . 1}$ $\mathrm{M} ;\left[\mathrm{N}_{2} \mathrm{H}_{5} \mathrm{OH}\right]_{\mathrm{wp}}=1.0 \mathrm{M}$; n-butanol/ isooctane containing 50 $\mathrm{mM}$ AG12 and $250 \mathrm{mM} \mathrm{H}_{2} \mathrm{O}$; reaction temperature $=25^{\circ} \mathrm{C}$; reaction time $=3 \mathbf{h}$. the Wo value. Figure 4 showed the plot of the mean diameters of silver nanoparticles prepared with hydrazine by the injection method against the Wo value in AG12 reverse micelles. As shown in Figure 4, the size of silver nanoparticles hardly changed with the Wo value in the present system, similar to the case of silver nanoparticles in reverse micelles of sucrose fatty acid esters [14]. On the other hand, the mean diameter of silver nanoparticles prepared with sodium borohydride showed $7.8 \mathrm{~nm}$ at Wo $=5$, while the mean diameter of silver nanoparticles prepared with hydrazine showed $14 \mathrm{~nm}$. The formation of nuclei is enhanced by using sodium borohydride compared to the case of hydrazine, since the reducing power of sodium borohydride is stronger than that of hydrazine [14]. The more number of nuclei are formed, the smaller the size of nanoparticles becomes. Accordingly, the size of silver nanoparticles obtained in the sodium borohydride system is smaller than that in the hydrazine system.

\subsection{Dependence of Reaction Temperature upon Size of Silver Nanoparticles}

Figure 5 shows the plots of the mean diameter of silver nanoparticles prepared with hydrazine by the injection method against reaction temperature. As seen in the figure, the mean diameter of silver nanoparticles tended to slightly increase with an increase in reaction temperature. The solubilization of reactants, the exchange of reactants between reverse micelles, the reduction reaction, and the growth of nanoparticles increase with increasing the reaction temperature [10,22-24].

\subsection{Dependence of Alkyl Chain Length of Surfactants upon Size of Silver Nanoparticles}

The formation and stability of micelles are due to the

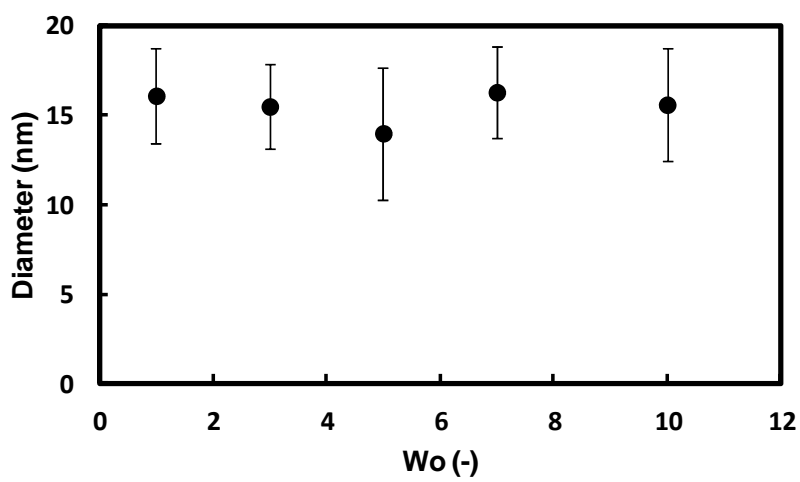

Figure 4. Effect of Wo value (the molar ratio of water to AG12) on the mean diameter of silver nanoparticles synthesized in AG12 reverse micelles by the injection method: $\left[\mathrm{AgNO}_{3}\right]_{\mathrm{wp}}=0.1 \mathrm{M} ;\left[\mathrm{N}_{2} \mathrm{H}_{5} \mathrm{OH}\right]_{\mathrm{wp}}=1.0 \mathrm{M} ;$ n-butanol/isooctane containing $50 \mathrm{mM}$ AG12 and a certain amount of $\mathrm{H}_{2} \mathrm{O}$; reaction temperature $=25^{\circ} \mathrm{C}$; reaction time $=3 \mathrm{~h}$. 


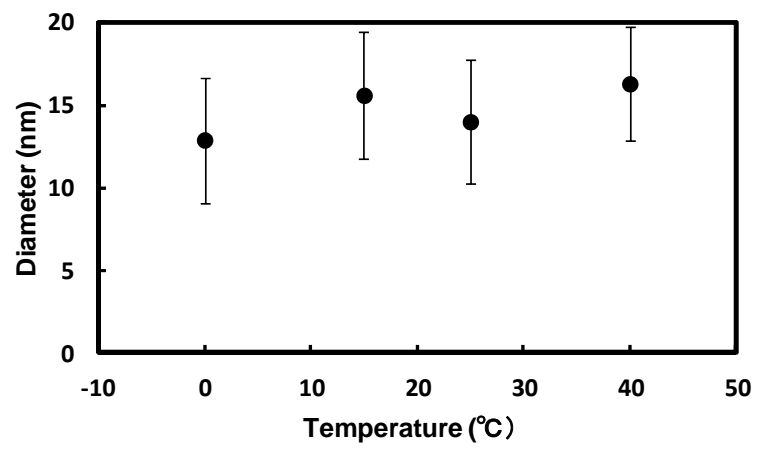

Figure 5. Effect of reaction temperature on the mean diameter of silver nanoparticles synthesized in AG12 reverse micelles by the injection method: $\left[\mathrm{AgNO}_{3}\right]_{\mathrm{wp}}=\mathbf{0 . 1} \mathrm{M}$; $\left[\mathrm{N}_{2} \mathrm{H}_{5} \mathrm{OH}\right]_{\mathrm{wp}}=1.0 \mathrm{M}$; n-butanol/isooctane containing 50 $\mathrm{mM}$ AG12 and $250 \mathrm{mM} \mathrm{H}_{2} \mathrm{O}$; reaction time $=3 \mathrm{~h}$.

structure and/or HLB of surfactants [25-27]. We have reported that the sizes of silver and palladium nanoparticles prepared in reverse micelles of sucrose fatty acid esters strongly depend on the average esterification degree of surfactants forming reverse micelles $[14,28]$. In the present work, we have examined the synthesis of silver nanoparticles in the reverse micelles of AG having a different alkyl chain length. Figure 6 shows the relation between the alkyl chain length of AG and the diameter of silver nanoparticles when silver nanoparticles were prepared with hydrazine in the reverse micellar system of AG having a different alkyl chain length for 3 $\mathrm{h}$ by the injection method. The diameter of silver nanoparticles appears to be independent upon the alkyl chain length from 8 to 12 . On the other hand, when the AG7 reverse micellar solution containing an aqueous solution of $\mathrm{AgNO}_{3}$ and the AG7 reverse micellar solution containing an aqueous solution of hydrazine were mixed, the formation of precipitate was immediately observed in the solution. This indicates that the dispersion efficiency of AG7 reverse micellar solution is not enough to spontaneously disperse silver nanoparticles formed in the solution. When AG8B was used, the formation of precipitate was observed after mixing the reactant solutions as well. It appeared that the hydrophobic group of AG8B was too bulky to disperse silver nanoparticles. From these results, it is suggested that the reverse micellar solution of AG having a linear alkyl chain at the alkyl chain length from 8 to 12 is suitable for preparing silver nanoparticles.

\subsection{Preparation of Silvar Nanoparticles through Solid-Liquid Extraction Method}

As the preparation of metal nanoparticles using reverse micelles does not require a special apparatus and extreme conditions of temperature and pressure, it is comparatively easy to expand the scale of reverse micellar reaction system. However, the productivity of metal nanopar-

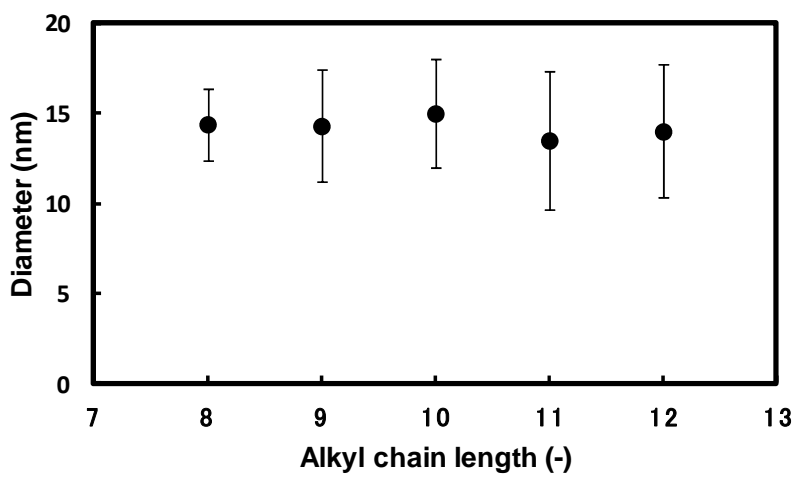

Figure 6. Effect of alkyl chain length of surfactants on the mean diameter of silver nanoparticles synthesized in AG reverse micelles by the injection method: $\left[\mathrm{AgNO}_{3}\right]_{\mathrm{wp}}=\mathbf{0 . 1} \mathrm{M}$; $\left[\mathrm{N}_{2} \mathrm{H}_{5} \mathrm{OH}\right]_{\mathrm{wp}}=1.0 \mathrm{M}$; n-butanol/isooctane containing 50 $\mathrm{mM}$ AG and $250 \mathrm{mM} \mathrm{H}_{2} \mathrm{O}$; reaction temperature $=25^{\circ} \mathrm{C}$; reaction time $=3 \mathrm{~h}$.

ticles per volume of reverse micellar system by the conventional injection method is limited due to low overall concentration of reactants in the reverse micellar system, since the volumetric ratio of water phase playing a role as the dissolution of reactants and the reaction field to the bulk organic phase is too small [6]. We have previously found out that the synthesis of silver nanoparticles is drastically promoted in reverse micelles of sucrose fatty acid esters by supplying solid reactants to the water pool through solid-liquid extraction [15]. The preparation of silver nanoparticles was examined in AG12 reverse micelles by the solid-liquid extraction method. The formation of silver nanoparticles was observed as seen in Figure 7. The colloidal solution of silver nanoparticles prepared by solid-liquid extraction method was much concentrated, compared to that prepared by the injection method mentioned above. The diameter of silver nanoparticles obtained by the solid-liquid extraction method was smaller than that obtained by the injection method. The resultant silver colloid could be preserved for at least one month without precipitation.

\section{Conclusion}

We have demonstrated that the alkyl glucoside/n-butanol/isooctane system is available for the synthesis of silver nanoparticles. The size of silver nanoparticles synthesized by the injection method was hardly influenced by the Wo value and the alkyl chain length of AG. The size of silver nanoparticles synthesized by the injection method dropped by switching from hydrazine to sodium borohydride as a reducing agent. The size of silver nanoparticles synthesized by the injection method tended to slightly increase with an increase in reaction temperature. The synthesis of silver nanoparticles was effectively promoted in the alkyl glucoside/n-butanol/isooctane system 

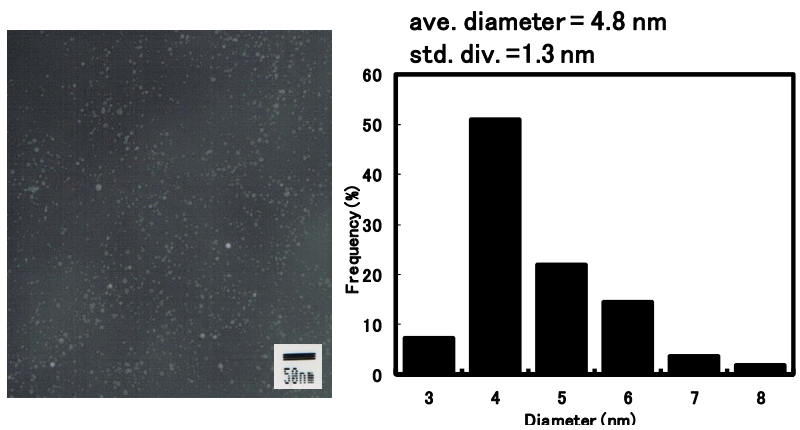

Figure 7. Transmission electron micrograph and particle size distribution of silver nanoparticles synthesized in AG12 reverse micelles by the solid-liquid extraction method: $\left[\mathrm{AgNO}_{3}\right]_{\mathrm{ov}}=0.1 \mathrm{M} ;\left[\mathrm{NaBH}_{4}\right]_{\mathrm{ov}}=1.0 \mathrm{M}$; n-butanol/isooctane containing $50 \mathrm{mM}$ AG12 and $40 \mathrm{mM} \mathrm{H}_{2} \mathrm{O}$; reaction temperature $=25^{\circ} \mathrm{C}$; reaction time $=3 \mathrm{~h}$.

by supplying reactants to the water pool through solidliquid extraction.

\section{REFERENCES}

[1] J. Zhang, P. Chen, C. Sun and X. Hu, "Sonochemical Synthesis of Colloidal Silver Catalysts for Reduction of Complexing Silver in DTR System,” Applied Catalysis A: General, Vol. 266, No. 1, 2004, pp. 49-54. http://dx.doi.org/10.1016/j.apcata.2004.01.025

[2] H. J. Lee, S. Y. Yeo and S. H. Jeong, “Antibacterial Effect of Nanosized Silver Colloidal Solution on Textile Fabrics,” Journal of Materials Science, Vol. 38, No. 10, 2003, pp. 2199-2204. http://dx.doi.org/10.1023/A:1023736416361

[3] Q. Zhang, Y. N. Tan, J. Xie and J. Y. Lee, "Colloidal Synthesis of Plasmonic Metallic Nanoparticles,” Plasmonics, Vol. 4, No. 1, 2009, pp. 9-22. http://dx.doi.org/10.1007/s11468-008-9067-x

[4] A. Sridhar, D. J. van Dijk and R. Akkerman, "Inkjet Printing and Adhesion Characterization of Conductive Tracks on a Commercial Printed Circuit Board Material,” Thin Solid Films, Vol. 517, No. 16, 2009, pp. 4633-4637. http://dx.doi.org/10.1016/j.tsf.2009.03.133

[5] J. Chen, Y. Luo, Y. Liang, J. Jiang, G. Shen and R. Yu, "Surface-Enhanced Raman Scattering for Immunoassay Based on the Biocatalytic Production of Silver Nanoparticles,” Analytical Sciences, Vol. 25, No. 3, 2009, pp. 347-352. http://dx.doi.org/10.2116/analsci.25.347

[6] J. H. Fendler, "Nanoparticles and Nanostructured Films: Preparation, Characterization and Applications,” WileyVCH, Weinheim, 1998. http://dx.doi.org/10.1002/9783527612079

[7] V. Uskokovic and M. Drofenik, "Synthesis of Materials within Reverse Micelles,” Surface and Review Letters, Vol. 12, No. 2, 2005, pp. 239-277. http://dx.doi.org/10.1142/S0218625X05007001

[8] P. Barnickel and A. Wokaun, "Synthesis of Metal Colloids in Inverse Microemulsions," Molecular Physics, Vol. 69, No. 1, 1990, pp. 1-9. http://dx.doi.org/10.1080/00268979000100011

[9] A. Taleb, C. Petit and M. P. Pileni, "Synthesis of Highly Monodisperse Silver Nanoparticles from AOT Reverse Micelles: A Way to 2D and 3D Self-Organization," Chemisty of Materials, Vol. 9, No. 4, 1997, pp. 950-959. http://dx.doi.org/10.1021/cm960513y

[10] R. P. Bagwe and K. C. Khilar, "Effects of Intermicellar Exchange Rate on the Formation of Silver Nanoparticles in Reverse Microemulsions of AOT," Langmuir, Vol. 16, No. 3, 2000, pp. 905-910.

http://dx.doi.org/10.1021/la980248q

[11] W. Zhang, X. Qiao, J. Chen and H. Wang, "Preparation of Silver Nanoparticles in Water-in-Oil AOT Reverse Micelles,” Journal of Colloid and Interface Science, Vol. 302, No. 1, 2006, pp. 370-373.

http://dx.doi.org/10.1016/j.jcis.2006.06.035

[12] Y. Okumura, "Organic Solvents and Surfactants for Toxicity Test Using Aquatic Organisms and Their Acceptable Concentrations," Bulletin of the National Research Institute of Fisheries Science, Vol. 11, No. 11, 1998, pp. 113134.

[13] P. D. Abel, "Toxicity of Synthetic Detergents to Fish and Aquatic Invertebrates,” Journal of Fish Biology, Vol. 6, No. 3, 1974, pp. 279-298. http://dx.doi.org/10.1111/j.1095-8649.1974.tb04545.x

[14] H. Noritomi, N. Igari, K. Kagitani, Y. Umezawa, Y. Muratsubaki and S. Kato, "Synthesis and Size Control of Silver Nanoparticles Using Reverse Micelles of Sucrose Fatty Acid Esters,” Colloid and Polymer Science, Vol. 288, No. 8, 2010, pp. 887-891. http://dx.doi.org/10.1007/s00396-010-2214-x

[15] H. Noritomi, Y. Umezawa, S. Miyagawa and S. Kato, "Preparation of Highly Concentrated Silver Nanoparticles in Reverse Micelles of Sucrose Fatty Acid Esters through Solid-Liquid Extraction Method," Advances in Chemical Engineering and Science, Vol. 1, No. 4, 2011, pp. 299304. http://dx.doi.org/10.4236/aces.2011.14041

[16] N. Otomo, "Self-Organized Structures of Food Emulsifiers and Their Applications,” Japan Journal of Food Engineering, Vol. 4, No. 1, 2003, pp. 1-9.

[17] H. Noritomi, S. Tamai, H. Saito and S. Kato, "Extraction of Water Miscible Organic Dyes by Reverse Micelles of Alkyl Glucosides," Colloid and Polymer Science, Vol. 287, No. 4, 2009, pp. 455-459. http://dx.doi.org/10.1007/s00396-008-1988-6

[18] A. Henglein, "Physicochemical Properties of Small Metal Particles in Solution: 'Microelectrode' Reactions, Chemisorption, Composite Metal Particles, and the Atom-toMetal Transition,” Journal of Physical Chemistry, Vol. 97, No. 21, 1993, pp. 5457-5471. http://dx.doi.org/10.1021/j100123a004

[19] P. L. Luisi and B. E. Straub, "Reverse Micelles: Biological and Technological Relevance of Amphiphilic Structures in Apolar Media,” Plenum Press, New York, 1984.

[20] D. H. Chen, C. C. Wang and T. C. Huang, "Preparation of Palladium Ultrafine Particles in Reverse Micelles,” Journal of Colloid and Interface Science, Vol. 210, No. 1, 1999, pp. 123-129.

http://dx.doi.org/10.1006/jcis.1998.5795 
[21] F. J. Arriagada and K. Osseo-Asare, "Synthesis of Nanosize Silica in a Nonionic Water-in-Oil Microemulsion: Effects of the Water/Surfactant Molar Ratio and Ammonia Concentration,” Journal of Colloid and Interface Science, Vol. 211, No. 2, 1999, pp. 210-220. http://dx.doi.org/10.1006/jcis.1998.5985

[22] W. L. Hinze, "Organized Assemblies in Chemical Analysis Vol. 1: Reverse Micelles,” JAI Press Ltd., Greenwich, London, 1994.

[23] C. Tojo, M. C. Blanco and M. A. Lopez-Quintela, "The Influence of Reactant Excess and Film Flexibility on the Mechanism of Nanoparticle Formation in Microemulsions: A Monte Carlo Simulation,” Langmuir, Vol. 14, No. 24, 1998, pp. 6835-6839. http://dx.doi.org/10.1021/la9806931

[24] J. P. Cason, M. E. Miller, J. B. Thompson and C. B. Roberts, "Solvent Effects on Copper Nanoparticle Growth Behavior in AOT Reverse Micelle Systems,” Journal of
Physical Chemistry B, Vol. 105, No. 12, 2001, 22972302. http://dx.doi.org/10.1021/jp002127g

[25] D. J. Shaw, "Introduction to Colloid and Surface Chemistry,” Butterworth-Heinemann, Oxford, 1992.

[26] J. N. Israelachvili, "Intermolecular and Surface Forces," Academic Press Ltd., London, 1985.

[27] D. J. Mitchell and B. W. Ninham, "Micelles, Vesicles, and Microemulsions," Journal of the Chemical Society, Faraday Transactions 2, Vol. 77, No. 4, 1981, pp. 601629. http://dx.doi.org/10.1039/f29817700601

[28] H. Noritomi, K. Kagitani, Y. Muratsubaki and S. Kato, "Effect of Composition of Sucrose Fatty Acid Esters on Formation of Palladium Nanoparticles in Reverse Micelles. Colloid and Polymer Science, Vol. 287, No. 7, 2009, pp. 795-799.

http://dx.doi.org/10.1007/s00396-009-2031-2 